Instructions for authors, subscriptions and further details:

http://rasp.hipatiapress.com

\title{
Análisis de la Coherencia entre el Proceso Pictórico de Yves Klein y la Idea de Duplicidad en sus Monocromos de la Serie IKB-International Klein Blue
}

Jaume Fortuny ${ }^{1}$

1) Facultad de Bellas Artes, Universidad de Barcelona. España

Date of publication: February $3^{\text {rd }}, 2017$

Edition period: February 2017-June 2017

To cite this article: Fortuny, Jaume. (2017). Análisis de la coherencia entre el proceso pictórico de Yves Klein y la idea de duplicidad en sus monocromos de la serie IKB-International Klein Blue. Barcelona, Research, Art, Creation, 5(1), 92-125. doi: 10.17583/brac.2017.2509

To link this article: http://dx.doi.org/10.17583/brac.2017.2509

PLEASE SCROLL DOWN FOR ARTICLE

The terms and conditions of use are related to the Open Journal System and to Creative Commons Attribution License (CC-BY). 

pp. $92-125$

\section{Analysis of the Coherence between the Pictorial Process of Yves Klein and the Idea of Duplicity in his Monochromes of the Series IKB-International Klein Blue}

Jaume Fortuny

Faculty of Fine Arts, University of Barcelona. Spain

(Received: 16 January 2017; Accepted: 23 January 2017; Published: 3 February 2017)

\section{Abstract}

Research aimed to understand how Yves Klein created the new colour International Klein Blue and to collect the data needed to define the object of his specific actions on his canvas and any other surfaces named IKB. Research of this kind sought to improve our understanding of the technological aspects underlying the science of colour and its duplicity. The methodology that was used in the process of analysis was the technology of industrial painting, spectrophotometry and colorimetry, and it was with the aim of confirming the aesthetic experience described in the reviews on the IKB and the idea of duplicity. The intensity, tone, subtone, dominant wavelength, luminosity, brightness, gloss, refractive index and paint viscosity were analysed. The results of the analysis showed that this blue was not a new colour, and that it also did not have an exceptional intensity. Klein failed to duplicate his IKB.

Keywords: creative process, duplicity, Yves Klein, monochrome, IKB-International Klein Blue 

pp. $92-125$

\section{Análisis de la Coherencia entre el Proceso Pictórico de Yves Klein y la Idea de Duplicidad en sus Monocromos de la Serie IKB-International Klein Blue}

Jaume Fortuny

Facultad de Bellas Artes de la Universidad de Barcelona. España

(Recibido: 16 enero 2017; Aceptado: 23 enero 2017; Publicado: 3 febrero 2017)

\section{Resumen}

La investigación buscó comprender cómo Yves Klein creó el nuevo color Internacional Klein Blue y recoger los datos necesarios para definir el objeto de sus acciones específicas en su lienzo y en cualquier otra superficie denominada IKB. Una investigación de este tipo intentó mejorar nuestra comprensión de los aspectos tecnológicos subyacentes a la ciencia del color y su duplicidad. La metodología utilizada en el proceso de análisis fue la tecnología de la pintura industrial, espectrofotometría y colorimetría, y fue con el objetivo de confirmar la experiencia estética descrita en las reseñas sobre el IKB y la idea de su duplicidad. Se analizaron la intensidad, el tono, el subtono, la longitud de onda dominante, la luminosidad, el brillo, el lustre, el índice de refracción y la viscosidad de la pintura. Los resultados del análisis mostraron que este azul no era un color nuevo y que tampoco tuvo una intensidad excepcional, y que Klein no logró duplicarlo.

Palabras clave: proceso creativo, duplicidad, Yves Klein, monocromo, IKBInternational Klein Blue

2017 Hipatia Press

ISSN: 2015-8992

DOI: $10.4471 /$ brac.2017.2509

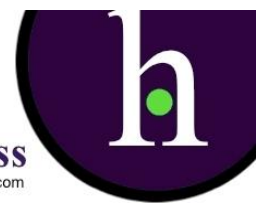


ualquiera de nosotros recordará que aprendimos a entender el trabajo de Yves Klein como una operación estética, y no como una obra de arte, a través de manuales como, por ejemplo, el de Giulio Carlo Argan (1984). Este tipo de monografías sobre arte moderno afirman que Klein cubre la superficie del lienzo con un sólo color sin la más mínima variación - nuestra investigación parte de la sospecha de que esto es cuando menos incierto- y con ello pretende que la experiencia estética de nuestra recepción como espectadores viva un azul como ritual que disponga a sentir un arte puro gracias a deshacerse de cualquier procedimiento técnico — creemos que esto debe ser falso y lo analizaremos aquí- y, de este modo, todos hemos estado sosteniendo que Klein logra desmitificar el acto artístico $\mathrm{y}$, por consiguiente, acabar con aquello a lo que la sociedad atribuye un valor —destreza. Todo para lograr el objetivo siguiente:

"Si el artista ya no es poseedor de una técnica, si ya no produce objetos valorables, no puede haber una crítica que juzgue a posteriori y si la operación estética es la elección o juicio, no puede haber dos juicios, uno antes (artista) y otro después (crítico). Por otra parte, el puro acto del artista sería incomunicable y no tendría duración si no estuviera verbalizado por el crítico, primer fruidor y privilegiado que ofrece al público el modelo de una fruición eficaz, pero también difusor de un discurso que es parte integrante de la operación estética." (Argan, 1984, p. 655)

La intencionalidad de los objetos monocromos deYves Klein fue convertir la experiencia estética de nuestra recepción en la misma que ocurre con los productos industriales, donde ya no está en juego ni una técnica ni un estilo. El lienzo monocromo ya lo encontramos en la serie Blanco sobre blanco de Kazimir Malevich en 1918. Aunque, en este primer caso, monochromos no implica vacuidad o ausencia de la imagen, porque sobre el cuadrado blanco del lienzo aparece dispuesto oblicuamente uno más pequeño de idéntico tono pero con diferente toque de pincel. Prácticamente al mismo tiempo que las experiencias monocromas de Lucio Fontana respecto a una pintura como soporte de un hueco, encontramos otras con distintas intenciones: las debidas a Piero Manzoni y sus pinturas blancas con objetos inusuales o bien objetos inusuales pintados con el azul ultramar característico de Yves Klein, así como la serie de cuadros completamente 
blancos de Robert Rauschenberg, donde la única imagen es la sombra del espectador. Aracil y Rodriguez (1983, p. 372) describen esta década de los cincuenta como la voluntad de conseguir una pintura objetual y conceptual al mismo tiempo y aceptan el término espaces imaginaires [espacios imaginarios] -acuñado por el crítico de arte francés Pierre Restany para referir este tipo de pintura- porque estos autores entienden la superficie del lienzo como la presencia de un espacio psicológico, donde vienen a insertarse las emociones individuales. Sin embargo, esta la descripción como espacios imaginarios es válida para cualquier superficie, pues tanto para dar forma a una figura-abstracta como a una figura-figurativa es necesario entregarse a la consideración de lo que se tiene en el pensamiento, y esta idéntica necesidad de operar intelectualmente demuestra la absurdidad de la diferencia entre presentar figuradamente o representar mediante la figuración. Pensemos, por ejemplo, que cualquier aficionado al ajedrez sabe reconocer el movimiento del caballo aunque esta pieza no se represente figurativamente y sea presentada figuradamente con una letra ele. Por consiguiente, si sabemos enjuiciar la figuración azulada de La Parisiènne (1874) de Pierre Auguste Renoir, no podemos dejar de hacer lo mismo con la abstracción del IKB 3-Monochrome bleu (1960) de Yves Klein y su presuntamente NUEVO azul. De aquí en adelante, escribiremos en mayúscula cada adjetivación que los críticos de arte dieron al sustantivo (azul) de Klein. En el texto también encontraremos en cursiva las palabras de la ciencia del color que están bajo sospecha en nuestra investigación, con ello pretendemos favorecer la dinámica de lectura de este artículo elaborado a través de conceptos de la química y de la física pero pensado para lectores del ámbito de las humanidades.

Llevar a juicio esta novedad no parece tarea fácil. Los observadores medios tienden a poder diferenciar unos ciento cincuenta colores base (matices), pero hay dos maneras de convertirlos en muchos más. En una podemos modificar su luminosidad. En otra, podemos variar la intensidad de cada color base o, lo que es lo mismo, cambiar su saturación. Es decir, si a una luz roja le añadimos blanco, veremos el color rosa resultante menos saturado que el rojo inicial porque la saturación está inversamente relacionada con la cantidad de blanco que haya en el color; así, un color estará más saturado cuanto menos blanco contenga. Por tanto, cada uno de 
los ciento cincuenta colores base discriminables puede tener muchos valores de intensidad y luminosidad. Se ha estimado que podemos discriminar siete millones de colores diferentes (Goldstein, 1993, p. 122). También se puede intentar determinar el número de colores que percibimos contando los nombres con que los designamos; por ejemplo, podemos compilar siete mil quinientos nombres de colores diferentes (Judd \& Kelly, 1955, p. 1). Obviamente, siete millones e incluso siete mil quinientos son demasiados colores para poder trabajar con ellos; por eso, los científicos del color buscan trabajar sólo con unos cuantos colores básicos. "La lista más pequeña fue propuesta por Leo Hurvich (1981), que mantiene poder describir todos los colores discriminables usando únicamente seis términos y sus combinaciones. Estos términos son rojo, amarillo, verde y azul para los colores cromáticos, y blanco y negro para los colores acromáticos." (Goldstein, 1993, p. 122). Así, para que el color azul de Klein lograra ser un color realmente NUEVO, debió dar a conocer un pigmento que provocara una sensación cromática azulada que no lograsen asociar a ninguno de aquellos términos o sus combinaciónes.

Podemos encontrar más de setecientas especies químicas consideradas como pigmentos y, en algunas de ellas, diversos sistemas de cristalización que pueden variar sus propiedades, por lo que las familias de estas especies químicas deben conocerse para poder aprehender satisfactoriamente los efectos plásticos deseados. Es bastante frecuente que las marcas comerciales sigan criterios de denominación diferentes y que utilicen nombres tradicionales o genéricos. El azul de Prusia tiene como sinónimos el azul de París, de Berlín, de Amberes o de Milori, pero todos ellos son ferrocianuro férrico. Este problema fue resuelto por la Society of Dyers and Colourists (1975) al establecer una denominación común mediante la clasificación Colour Index, que identifica productos de la misma especie química particularizando la composición y tipo de cristalización. De manera que el Pigment Blue 27 corresponde al azul de Prusia y todos sus sinónimos siendo la fórmula $\left[\mathrm{KFe} \cdot \mathrm{Fe}(\mathrm{CN}) 6 \cdot \mathrm{H}_{2} \mathrm{O}\right]$ o bien $\left[\mathrm{NH} 4 \mathrm{Fe} \cdot \mathrm{Fe}(\mathrm{CN}) 6 \cdot \mathrm{xH}_{2} \mathrm{O}\right]$ mientras que el Pigment Blue 15 identifica a todos los azules de ftalocianina y el Pigment Blue 15:3 un azul de ftalocianina pero cristalizado en forma $\beta$. La legalidad vigente obliga a que todas las cartas de colores comercializados incluyan este tipo de clasificación, por lo que es fácil que nos familiaricemos 
con ella. Es cierto que el Colour Index permite caracterizar suficientemente un producto. Sin embargo, recordemos que el tamaño de las partículas elementales puede dar unas características ópticas diferentes, y lo mismo sucede cuando varía su forma o su estado de aglomeración. Aquí, sólo nuestro grado de profesionalidad puede advertir el problema. Si el pigmento es la causa del carácter cromático (color, opacidad, y brillo) es consecuente la necesidad de conocer qué tipo de partículas se utilizaba en el momento de su producción. Mediante los objetos monocromos de la serie IKB pintados con el célebre International Klein Blue, Yves Klein logr(aría) una sensación cromática no catalogada por el Colour Index. Al menos así se lo pareció a los críticos de arte que escribieron sobre cómo apareció este estímulo intelectual en la Historia del Arte.

Klein define su color como un azul ultramar, descripción que lo equipara con el lapislázuli, denominación medieval de la piedra semipreciosa lazurita y conocida como azul ultramar, porque el lapislázuli provenía de la otra parte del mar. Se emplea desde la antigüedad y en Europa desde el siglo XII hasta el siglo XVIII y hoy difícilmente se encuentra en el mercado. El manual de procedimientos pictóricos de Doerner (1991, p. 50) describe cómo el químico Guimet lo obtuvo sintéticamente en 1828 y cómo en 1830 fue fundada la primera fábrica de ultramarino artificial en Francia, pero no menciona las características de la partícula de este producto sintético y se limita a sus problemas en diversos medios. El catedrático Pedrola (1988, 48, p. 61) advierte de la importancia de la granulometría en el grado de coloración pero desatiende a que el ultramarino artificial tiene mucha menos luminosidad y poca más intensidad que el natural (lapislázuli) para atender a cuestiones de coste y estabilidad, por lo que la notación química que ofrece en su libro queda como mera decoración. Ni siquiera Mayer (1993, 77, p. 149) atiende al caso en su libro, la monografía técnica más loada en Bellas Artes, pues se limita a recordar que sólo son diferenciables al microscopio por su estructura cristalina. Todos estos manuales académicos sobre procedimientos pictóricos parecen obviar las características de la partícula de pigmento. No comprendemos esta carencia, porque la razón de la importancia de la materialización del vehículo expresivo está en que la causa del color no es más que un juego de electrones (Allen, 1970; Gall, 1971; Nassau, 1983; Zollinger, 1991). Kurt Nassau (1980) resume esta causalidad 
del mundo multicolor en catorce categorías diferentes que tienen su origen en la ocurrencia de ciertos cambios en el estado de los electrones, cambios que existen en la materia como respuesta a su interacción con las diferentes longitudes de onda de la luz, y lo engloba en estos cinco grandes grupos de fenómenos productores de color: transiciones electrónicas en los átomos e iones libres, colores del campo cristalino, transiciones entre orbitales moleculares, transiciones en materiales que poseen bandas de energía, y la óptica geométrica y física

En arte suele mencionarse la luz pero muy poco la longitud de onda, mucho menos la frecuencia y nunca se referencia la energía, salvo en su acepción figurada para una finalidad literaria. No obstante, todos son términos alternativos para caracterizar el fenómeno de la onda luminosa que provoca nuestra sensación cromática. La energía es directamente proporcional a la frecuencia, y ambas son inversamente proporcionales a la longitud de onda. Es decir, frecuencias y energías bajas corresponden a longitudes de onda largas, como es el caso del rojo en el espectro visible (véase Figura 1). La unidad más utilizada en la medida de longitudes de onda es el nanómetro $\left(1 \mathrm{~nm}=10^{-9} \mathrm{~m}\right)$ mientras que la energía de la luz se suele medir en electronvoltio (eV), y cada unidad equivale a la energía que adquiere un electrón cuando es acelerado por una diferencia de potencial de un volt. De este modo, si tomamos la longitud de onda como referencia, la visión humana abarca desde los $700 \mathrm{~nm}$ (este límite entre la luz roja y la radiación infrarroja puede llegar a los $780 \mathrm{~nm}$ ) hasta los $400 \mathrm{~nm}$ (este límite entre la luz violeta y la radiación ultravioleta puede llegar a los $380 \mathrm{~nm}$ ); mientras que si lo expresamos en unidades de energía, el mismo intervalo se extiende entre $1.77 \mathrm{eV}$ (rojo) y $3.1 \mathrm{eV}$ (violeta).

La onda luminosa es una radiación electromagnética y todas las interacciones de este tipo de radiación con la materia vienen determinadas por el siguiente principio de la mecánica cuántica: los átomos tan sólo pueden existir en determinados estados discretos que se caracterizan por poseer cada uno de ellos una determinada energía y tener prohibidas las energías intermedias a éstas. Podemos caracterizar cada átomo por la energía mínima posible que corresponde a lo que denominamos su estado fundamental y toda una serie de estados excitados de energías progresivamente más elevadas; lo que nos permite comparar los estados de 
energía permitida con los peldaños de una escalera, aunque su espaciado sea muy irregular. La luz, o cualquier otra radiación, sólo puede ser absorbida cuando la energía que transporta sea exactamente la necesaria para promocionar a un átomo de un peldaño a otro superior. Del mismo modo, cuando la transición es desde un estado excitado hasta otro de inferior energía, el átomo emite una radiación cuya energía será igual a la diferencia entre las energías correspondientes a los dos niveles. Esta energía aparece en forma de un fotón o cuanto de luz cuya frecuencia y longitud de onda vienen determinados por dicha diferencia de energías. Así pues, el fenómeno del color refiere la diversidad de niveles energéticos electrónicos.

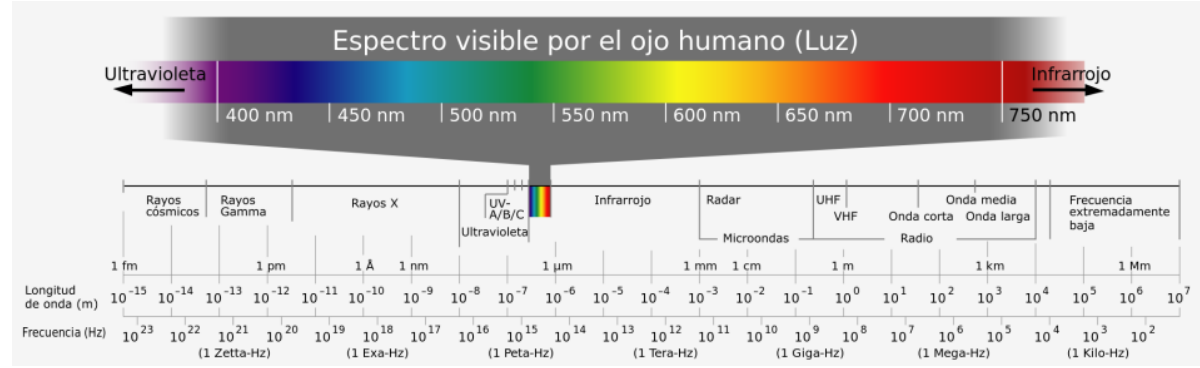

Figura 1. Equivalencias entre longitudes de onda y frecuencias en el espectro visible por el ojo humano. Recuperada de https://commons.wikimedia.org/wiki/File:Electro magnetic_spectrum-es.svg. Public domain.

Por lo visto hasta aquí, nada diferencia una producción industrial de una pintura artística, y ambas comparten las mismas causas del color con cualquier objeto de nuestro alrededor. Entonces, toda adjetivación que adherimos a la palabra "color" debería tener su razón en la imperfección de las redes cristalinas, en la regularidad de las caras de los cristales, en su forma, en su tamaño, y en su distribución en la capa de pintura. Entonces, si estas características del pigmento -que causan el color- determinan un índice de refracción de la luz que lo diferencia del medio que lo envuelve, el caso de nuestro azul INTENSO deberá ofrecer el mayor número posible de refracciones para que su carácter no pierda intensidad. Esto significa que la capa de pintura deberá contener el mayor número posible de partículas de 
pigmento y que éstas tengan diferentes tamaños, puesto que no deben quedar espacios entre las partículas, pues la capa pierde posibilidades de refracción $\mathrm{y}$, en consecuencia, intensidad. Esto puede verse claramente si en la Figura 2 dibujamos partículas esféricas del mismo diámetro que se tocan entre sí, de este modo quedan entre ellas espacios más pequeños que pueden ser ocupados por partículas de la misma naturaleza química (el mismo tono) y de la misma forma esférica (la misma propiedad óptica). Por tanto, no debemos confundir la intensidad con la luminosidad (que podemos equiparar con la cantidad de blanco), pues es la cantidad de luz que devuelve la superficie; ni con el brillo, que lo causa la reflexión especular.
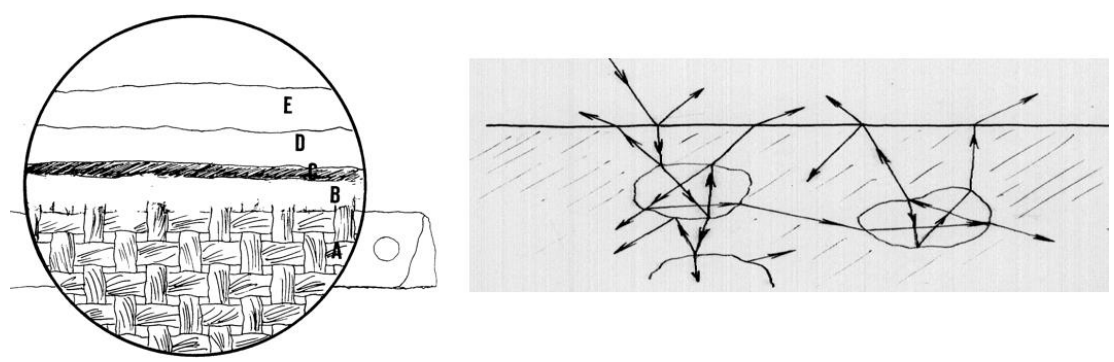

Figura 2. A la izquierda: esquema de la sección microscópica del perfil de un lienzo: fibra de la tela (A), preparación magra (B), primera capa magra y de secado rápido $(\mathrm{C})$, segunda capa más grasa que la primera (D), tercera capa más empastada que la segunda (E). Las capas más próximas a la tela siempre deben tener menos contenido de aglutinante, que aumentará cuanto más superior sea la capa. Esta norma de graso sobre magro permite que la capa inferior seque antes que la superior y, así, permite afianzar una segunda capa sobre la primera. En el caso de una capa seca que debajo tenga una todavía húmeda, los vapores desprendidos durante el proceso de secado se acumulan entre las capas tensionando la superior hasta romperla. Dibujo del autor. A la derecha: fenómeno de difusión de la luz que causa la sensación cromática en la capa de pintura. La luz (proveniente del aire a través del aglutinante) es dispersada (conjunto de reflexiones y refracciones) al encontrar la partícula de pigmento y devuelta al aire o transmitida de partícula a partícula, que en este caso es un cristal irregular. Dibujo del autor adaptado de Ramos y De María (1988). 
Por consiguiente, a partículas más finas más ocupación del espacio por evitar huecos y, así, mayor superficie donde pueda reflejarse la luz. Entonces, el actual pigmento ultramar puede ofrecer más intensidad que el pigmento antiguo (lapislázuli) gracias a su menor tamaño de partícula, sin que esta diferencia se deba a la constante -por fácil pero falsaargumentación del olvido de las técnicas de los grandes maestros por parte de los pintores contemporáneos. Del mismo modo, ofrecerá menos luminosidad que el lapislázuli porque su mayor partícula ocupa menos superficie y, así, absorbe menos luz que el actual ultramar artificial; o lo que es lo mismo, re-emite más energía.
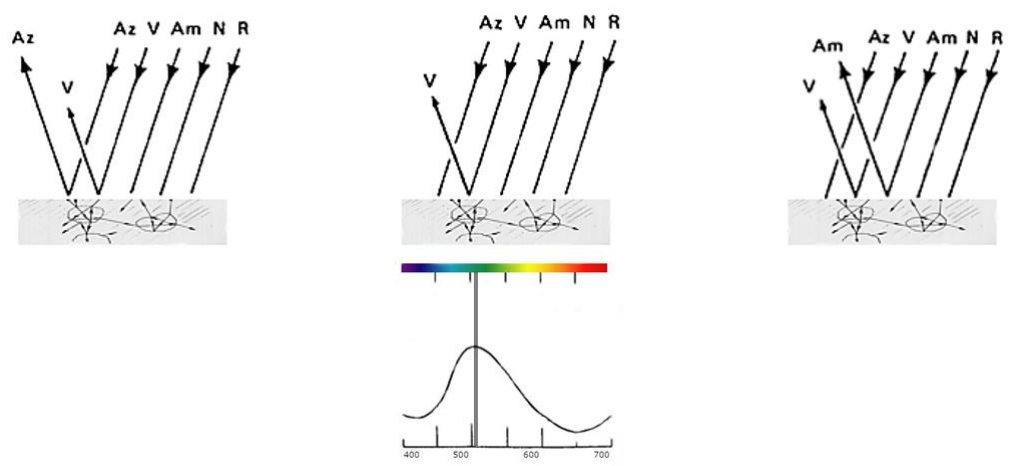

Figura 3. Arriba a la izquierda una pintura azul y amarilla que no absorben todo el verde, por lo que el resultado de su mezcla difunde luz verde. En el centro una pintura verde y abajo su curva de reflectancia espectral típica, donde la línea indica la longitud de onda dominante de $506 \mathrm{~nm}$ cuyo equivalente es un verde azulado. Dibujo del autor adaptado de McAdam, (1985) y de Goldstein (1993).

El ultramar aparece relativamente oscuro a causa de que sus partículas absorben cerca del 75 por ciento de la luz que cae sobre ellas, mientras que el lapislázuli sólo lo hace cerca del 49 por ciento, por lo que el lapislázuli nos parece más cercano al blanco que el ultramar. Ambos reflejan una estrecha banda en la región azul-violeta del espectro de color y algo de luz roja pero muy poca verde, motivo por el que no ofrecerán verdes brillantes 
cuando se mezclan con amarillo (véase Figura 3). Es cierto que el lapislázuli tiene su longitud de onda dominante en $474.4 \mathrm{~nm}$ y el actual ultramar en $467.8 \mathrm{~nm}$, pero esta diferencia menor de $10 \mathrm{~nm}$ hace que sean prácticamente indiferenciables a simple vista, y es debida a que en la creación sintética del ultramar se buscó copiar la composición química como muestra la Figura 4.

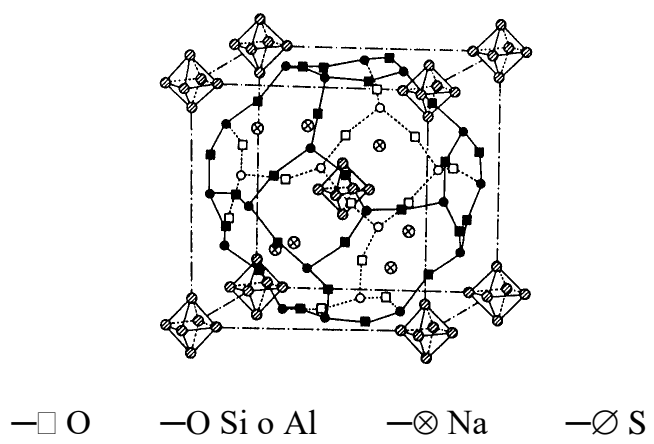

Figura 4. Cristal estándar del lapislázuli y del pigmento ultramarino artificial. Dibujo del autor adaptado de Buxbaum (1993).

Ambos pigmentos son polisulfuros de silicato complejos de diversas composiciones en las que las proporciones de Sodio y Sulfuro caracterizarán el color [ $\mathrm{Na}(6.9) \mathrm{Al}(5.6) \mathrm{Si}(4.6) \mathrm{O} 24 \mathrm{~S}(2.4)]$. Se determinó un estándar para su partícula primaria, pero no es usual reconocer la estructura cristalina del lapislázuli porque sólo ocasionalmente aparece en forma poliédrica. Por lo común, este mineral presenta partículas de forma angular y aplanada de tamaños irregulares, por lo que su disposición en la capa de pintura puede variar notablemente su color.

En el cristal estándar tanto para el lapislázuli como para el pigmento ultramar de la Figura 4, los radicales de aniones $\mathrm{S}_{3}{ }^{-}$provocan su color AZUL DE MATIZ ROJIZO porque son los responsables de la resonancia electrónica en la molécula, donde el alto contenido en Sílice produce este azul rojizo y el bajo da un producto verdoso. El ión positivo $\mathrm{Na}^{+}$es el responsable de que se mantenga la estructura poliédrica gracias a que ocupa sus intersticios, de modo que al reducir el contenido en sodio y azufre podemos obtener colores 
del rosa al violeta. Si recordamos las causas del color mencionadas anteriormente, podemos entender que las características ópticas sean las mismas y que sólo varíen por la proporción de componentes o la presencia de impurezas, así como por el tamaño de partícula. La misma composición pero con partículas de mayor tamaño provoca un azul de tono más oscuro con menor subtono rojizo y las de menor tamaño dan un tono más claro y subtono mas verdoso. Algo suficientemente importante si tenemos en cuenta que el tamaño de partícula del ultramarino producida por la industria raramente llega a $10 \mu$ y suele oscilar desde $0.7 \mu$ a $5 \mu$ mientras que en pinturas antiguas es común encontrar partículas de lapislázuli de $30 \mu$. Por tanto, las partículas de pigmento de las pinturas de Klein pod(rían) ser seis veces más pequeñas que en las pinturas antiguas y, cuanto menos, tres veces más pequeñas.

Respecto al índice de refracción del ultramar, puesto que es relativamente bajo $(1,55)$ podemos predecir que su color aparecerá más cerca de su propio tono en el temple de huevo que en aceite $(1,48)$ o acetato de polivinilo $(1,46)$ porque aquel temple tiene un índice de refracción más similar y no lo oscurece, hecho que también ocurrirá si la capa de aglutinante es gruesa o turbia (Parker, 1970, p. 120; Osborne, 1990, p. 15; Sonoda, Rioux \& Duval, 1993, p. 116; Roy, 1993, p. 41; Buxbaum, 1993, p. 124).

Alison Cole se doctoró en Arte del Renacimiento en el Instituto Warburg de Londres, y es conocida por sus publicaciones divulgativas sobre perspectiva y color. Cole (1994, p. 59) cree que Klein liberó al color de sus asociaciones emocionales al final de la década de 1950 para que existiera como obra de arte por sí mismo gracias a un azul BRILLANTE y excepcionalmente INTENSO de su propia invención y que llegó a patentar. En una nota técnica sobre el $I K B$, el conservador de la Colección Menil, Mancusi-Ungaro, sostuvo el uso de un color NUEVO y VIRGEN porque Yves Klein manipul(aría) hábilmente un pigmento con una resina sintética transparente y disolventes compatibles; lo que permit(iría) satisfacer las exigencias estéticas que pudo presentir el artista (1983, p. 247).

Así, según Mancusi-Ungaro, el azul ultramar elegido por Klein manten(dría) su VIBRACIÓN VISUAL particular y la RIQUEZA y PUREZA de tono gracias al aglutinante que une las partículas de pigmento al soporte, pues en los años cincuenta, este producto era a base de óleo, colas vegetales 
o animales, o bien a base de huevo, y todos ellos suavizan o mitigan el carácter del grano del pigmento y, por el contrario, Klein no alter(aría) su apariencia. Mancusi-Ungaro describe su aglutinante como el acetato de polivinilo que era comercializado bajo el nombre de Rhodopas M60A. Klein lo disuelve con alcohol etílico al 95 por ciento y acetato de etilo, por lo que según la proporción de disolvente, la pintura puede ser pastosa o fluida y con un secado más o menos rápido. Esto permite aplicarla a pincel, a pistola (véase Figura 5) o a rodillo, y esta maleabilidad posibilita que se adapte fácilmente tanto a la superficie absorbente de una esponja como a la resina de poliéster, es decir, casi sobre cualquier cosa.

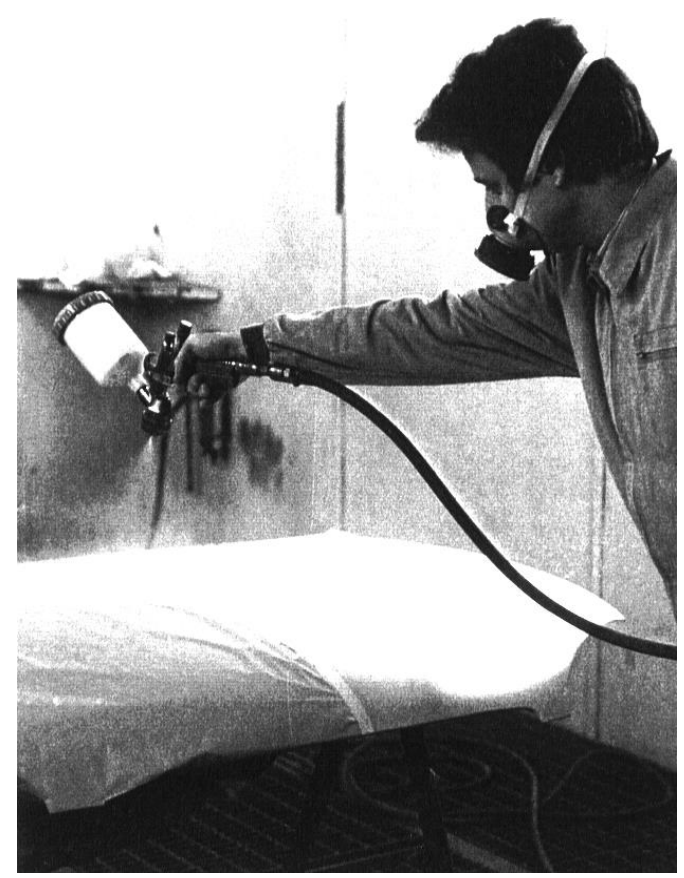

Figura 5. El autor pintando mediante pulverización por aire comprimido durante el curso de aplicación de la colorimetría de la Universidad Politécnica de Catalunya. La pistola es el aparato para transformar el chorro de pintura en una fina neblina que puede recubrir cualquier objeto al que se dirija. 
François Molnar (1992, p.72) sostiene mediante ingeniosos ejemplos que la singularidad del objeto artístico sólo es aparente y nada nos impide en Estética seguir el mismo método que en Física y comprobar lo propuesto mediante su confirmación en la experiencia. En este sentido, Molnar mantuvo que el famoso azul de Klein contiene casi lo mismo de rojo que de azul. Esta afirmación causó la estupefacción general porque fenomenológicamente la tela es azul, pero tal recepción no es una reacción afectiva ante la obra, sino la consecuencia de una actividad cognitiva.

La sospecha de la que partió nuestra investigación pudo darse gracias a entender que el ámbito original de la estética no es el arte sino la realidad, la naturaleza material o corporal. Así, estamos de acuerdo con Kamber (1993) en que no podemos hablar de arte sino de obra (work of art), pues lo inteligible -la materia de puro conocimiento, sin intervención de los sentidos- necesita de un candidato plausible que permita razonar a las personas sobre el paradigma que muestra. Probablemente, encontraremos la astuta sanción de quien entiende nuestro propio concepto de estética como absurdo, porque cuando apreciamos la elegancia de una demostración matemática, el goce es estético aunque el objeto de tal goce no es perceptivo en absoluto (Beardsley \& Hospers, 1982, p. 107). Para el caso, responderemos que "Albert Einstein calificó en cierta ocasión su pensamiento de interacción combinatoria de ciertos signos e imágenes más o menos claras, visuales o musculares, cuyos resultados habían de ser luego trabajosamente traducidos a palabras y otros signos abstractos." (Arnheim 1980, p. 265).

Recordemos que el significado etimológico de la palabra estética lo encontramos en Aisthetikós, palabra griega que denota lo que es perceptible a través de la sensación; así como en Aísthesis, la experiencia sensorial de la percepción (Van Lier, 1971, p. 146). La estética nace, pues, de un discurso del cuerpo. Es una forma de cognición a la que llegamos a través del gusto, el tacto, el oído, la visión, y el olfato -todo el sensorio corporal. Molnar parece que comparte nuestro concepto de estética, y esto le permite darse cuenta de que la cualidad del lienzo azul se debe a la riqueza que aportan los diversos colores (longitudes de onda), que son los que constituyen la energía re-emitida de este azul específico que mostramos en la Figura 6. 


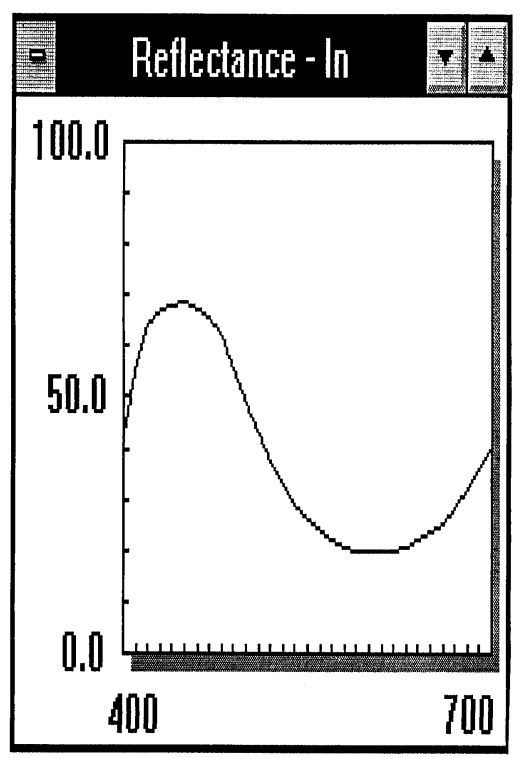

Figura 6. Curva de reflectancia espectral del IKB según los datos ofrecidos por Molnar (1992) adaptados a nuestro espectrofotómetro. La energía re-emitida a lo largo del espectro no corresponde sólo a la sensación de azul, sino también a la de verde y rojo, por lo que especifica una policromía. Este autor no ofrece los datos hasta $780 \mathrm{~nm}$ pero siguen la tendencia que muestra la figura hasta casi igualar el azul.

Además, si el aglutinante utilizado por Klein fue acetato de polivinilo -Rhodopas M60A- como Mancusi-Ungaro refiere para mostrar que este aglutinante no amarillea, no olvidemos que cualquier polímero oscurecerá bajo la luz y, en todo caso, el acrílico es el más permanente y no el polivinilo (Crighton, 1988, p. 14). Aunque los detalles exactos del método de trabajo son desconocidos, sabemos que la preparación de sus lienzos era al óleo pero 
utilizando distintos blancos y, por tanto, con diferentes índices de refracción: albayalde $(1,93)$, blanco de zinc $(2,03)$, o litopón $(2,37)$ sin mantener una preferencia (Sonoda, Rioux \& Duval, 1993, p. 116).

Recordemos ahora que la luz llega al espectador de dos maneras. Primero contiene algo de radiación reflejada en la primera superficie de incidencia después de atravesar la tenue capa de aceite donde no sufre alteración cromática, por lo que suele ser blanca como la incidente. Segundo, contiene mayor o menor proporción transmitida a través de la masa del pigmento, donde recibe la coloración correspondiente por selección de sus diversas longitudes de onda. La relación entre las cantidades de cada una de ellas y entre la luz reflejada total varía en función de la diferencia entre los índices de refracción del pigmento y del aglutinante que se ha empleado. Por ello, si el índice de refracción de la película de aceite de linaza va creciendo con el tiempo, tendremos una progresiva alteración del tono resultante. La experiencia demuestra que el cambio sufrido en nueve meses es suficiente para afectar la opacidad del albayalde (El Telar, 1951, p. 453). Por tanto, si la capa de azul IKB permit(iera) que la luz llegara a la preparación, perd(ería) la luminosidad que puede aportar el blanco además de ser modificada por el diferente índice de refracción de los blancos que utiliza indistintamente. Es más, el análisis fisicoquímico de Sonoda, Rioux y Duval (1993, p. 116) determina que el índice de refracción del acetato de polivinilo $(1,46)$ y el del pigmento ultramar $(1,55)$ no es el mismo, lo que permite afirmar que Klein se equivoca de aglutinante porque la yema de huevo tiene un índice de refracción más similar al de aquel pigmento y, así, no varía su característica óptica.

Por todo esto, no logrará la PUREZA que ve Mancusi-Ungaro. Tampoco podrá lograr la excepcional INTENSIDAD que le atribuye Alison Cole, puesto que la vibración visual del $I K B$ es debida a su re-emisión de energía en el área espectral del rojo, que es el subtono del azul caracterizado por la longitud de onda dominante entre $467.8 \mathrm{~nm}$ y $474.4 \mathrm{~nm}$. Si un color es más intenso cuanto más estrecha es esta banda, el espectro de la Figura 6 no muestra tal excepcionalidad, más bien evidencia su falta de PUREZA, es decir, su POLICROMÍA, como podremos comprender a través de comparar las curva espectral de la Figura 7 con la del $I K B$ de la Figura 6 y con la del verde azulado de la Figura 3. 

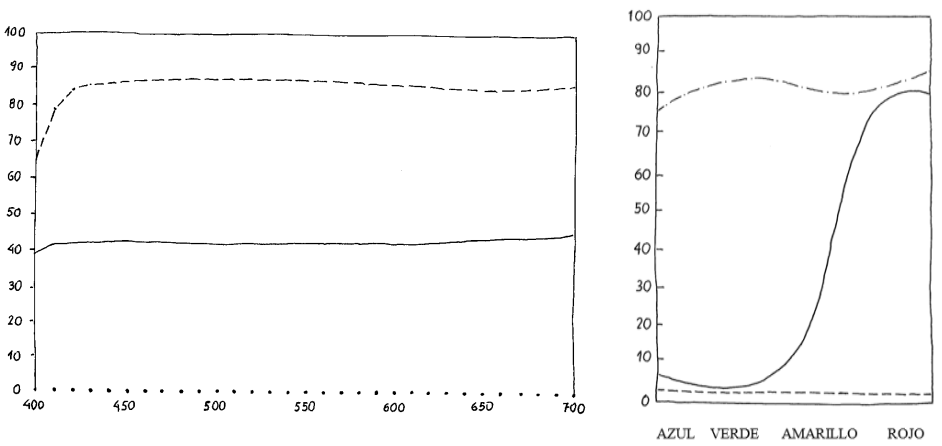

Figura 7. A la izquierda: espectro de reflectancia alta continua durante todas las longitudes de onda que caracteriza un color blanco (- - -) y a la derecha el espectro del blanco de un corrector para mecanografía. El mismo caso pero con una reflectancia media representa el espectro de un color gris $(-)$ y la de longitud de onda dominante en el rojo representa la curva de un bermellón. Para no ser un gris oscuro el negro debe mostrar una reflectancia $0(\ldots)$ pero este caso no puede darse porque no habría energía re-emitida, y es en este sentido que afirmamos que un negro puede ser un color bastante respetable, a la derecha el espectro del pigmento negro humo. En los casos que la curva no mantiene este paralelismo adquiere la forma que indica la tonalidad dominante en el objeto, como vimos en la Figura 6 y la Figura 3. Dibujo del autor adaptado de Westphal (1989).

Por supuesto, tenemos en cuenta que los críticos de arte pueden defender a Klein afirmando que este artista no era ni un físico ni un experto en colorimetría, por lo que utiliza el adjetivo monochrome como epíteto, como un término poético. Sin embargo, este argumento es difícilmente aceptable puesto que Yves Klein, aunque no un savant [erudito], sí era un homme averti [prevenido] por la industria de pinturas. Algo que demuestra el hecho de que probablemente fuera uno de los primeros pintores en utilizar el rodillo para intentar obtener la superficie perfectamente mate, pues aquel permite lograr la uniformidad de espesor de la capa de pintura (Parker, 1970, p. 474; Chauvel \& Roire, 1985, p. 27; González Martín, 1994, p. 141ss). 
Además, también sabía que durante su trabajo debía mirar sus telas con luz rasante a fin de controlar la reflexión de la superficie y, así, su brillo -que no es más que una luz rodeada por una luz menor (McLaren, 1986). Yves Klein $\operatorname{logr}($ aría) una superficie bastante mate teniendo en cuenta que para tal perfección debería realizarse en un laboratorio porque exige que la luz se refleje uniformemente en todas direcciones, lo que obliga a organizar sus $I K B$ en pequeñas partículas esféricas evitando su empaquetado por floculación como muestran la Figura 8.
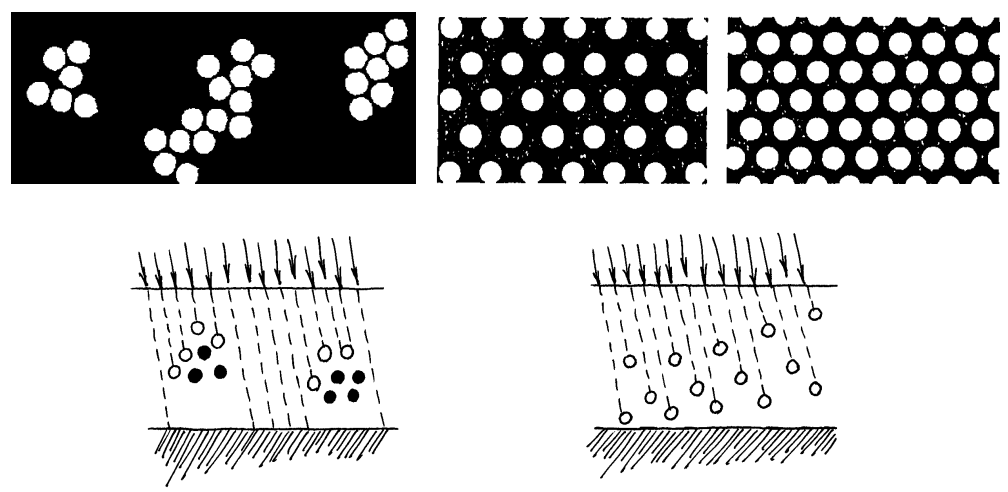

Figura 8. Arriba a la izquierda, floculación o efecto del empaquetado del pigmento y, a la derecha, separación entre partículas para diversas concentraciones de pigmento. Dibujo del autor adaptado de Parker (1970). Abajo a la derecha, capa de pintura bien dispersada que ofrece todas sus características ópticas y, a la izquierda, pigmento floculado que impide a la luz incidir directamente sobre todas las partículas, así llega al sustrato sin incidir en ellas y no ofrece toda su intensidad. Dibujo del autor.

Por tanto, cuando Alison Cole describe el IKB como azul BRILLANTE pod(ría) referir su luminosidad como claridad debida a la adición de blanco, algo que aumentaría el flujo luminoso y, así, aparecería con más luz en la evaluación psicológica con la que comúnmente nos referimos al objeto artístico. Sin embargo, este hecho también pod(ría) ser debido a la reflexión especular (véase Figura 9). 


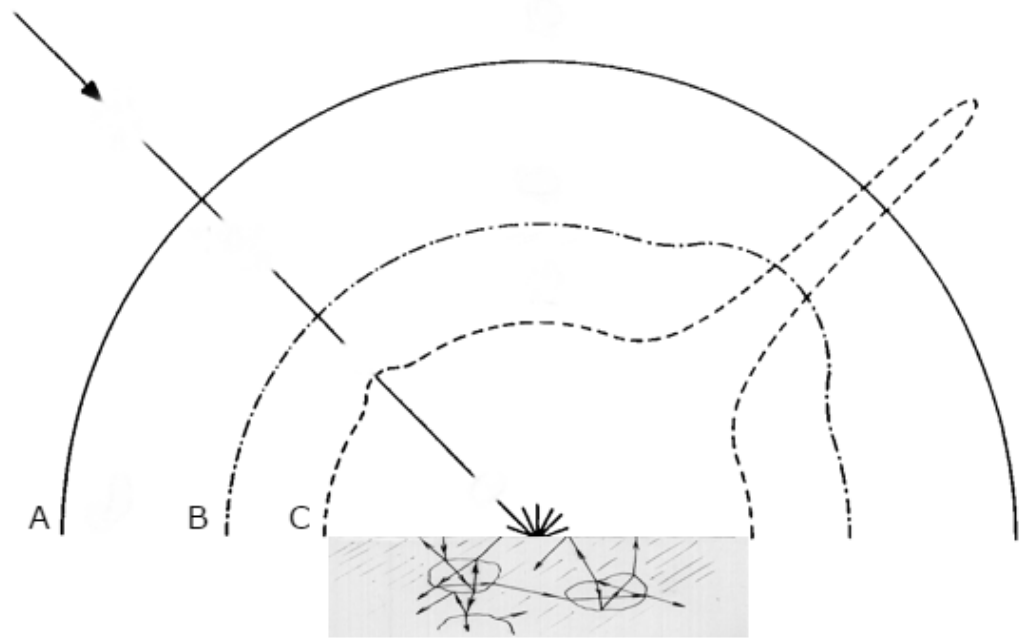

Figura 9. Efecto de brillo en la capa de pintura: (A) difusión perfecta, (B) acabado de cáscara de huevo por contraste entre áreas de reflexión especular y difusa, (C) pintura brillante a causa de su alta reflexión especular. Dibujo del autor adaptado de McLaren (1986).

Ante las declaraciones de Cole y las de Mancusi-Ungaro es necesario esclarecer la terminología recordando la utilizada a lo largo de nuestra concatenación. Si el aspecto cromático corresponde a una radiación pura, diremos que está totalmente saturado, y en el caso de que añadamos blanco, este aditivo lo desatura. Esta propiedad se define psicofísicamente como pureza y psicológicamente como saturación, y corresponde a la variación de un color que mantiene el mismo tono pero aclarándose paulatinamente. El tono es otra propiedad psicológica y su correspondiente psicofísico es la longitud de onda dominante. La siguiente tabla especifica las relaciones entre las magnitudes físicas, psicofísicas, y psicológicas, referidas a la cromaticidad. 


\begin{tabular}{|c|c|c|}
\hline MAGNITUD FÍSICA & MAGNITUD PSICOFÍSICA & $\begin{array}{c}\text { EVALUACIÓN } \\
\text { PSICOLÓGICA }\end{array}$ \\
\hline Flujo radiante $(\mathrm{W})$ & Flujo luminoso $(\mathrm{lm})$ & luz (brillo) \\
& Color - luminosidad & -claridad \\
& -cromaticidad & -tinta \\
& -long. onda dominante & -tono \\
& -pureza & -saturación \\
\hline
\end{tabular}

El brillo no está directamente relacionado con el color pero la percepción de los atributos visuales de un objeto relacionan el color con el brillo y la textura. El hecho real es que el brillo enmascara al color porque está directamente relacionado con la distribución del flujo reflejado difusamente (véase Figura 9). Los objetos que poseen brillo son esencialmente opacos y obligan a conocer cómo se distribuye el flujo alrededor del componente especular y cómo se modifica la reflectancia con el ángulo de incidencia, pues esta variación modifica la distribución espectral del flujo reflejado, es decir, cambia de color según el ángulo de observación. Precisamente, el azul ultramar tiene una gran aplicación sobre metales brillantes o sobre revestimientos de fondos blancos para darles efectos de color atractivos (Lozano, 1978, p. 361; Parker, 1970, p. 120). Por tanto, si es un pigmento transparente y, en realidad, si como afirman Sonoda, Rioux y Duval (1993, p. 116) Klein utiliza indistintamente diversos blancos para preparar sus telas, el flujo radiante o bien flujo luminoso, o la luz re-emitida que llega a nuestros ojos provocando el efecto cromático resultante no se(ría) la misma; puesto que las características ópticas del pigmento blanco del fondo no lo son.

Para nuestra cuestión, lo que interesa de la apariencia del brillo es cómo se distribuye el flujo reflejado (glossiness), pues esta distribución determina diferentes tipos de brillo (Lozano, 1978, p. 363ss, p. 140). Para el caso IKB, el brillo especular (specular) se(ría) poco evidente porque se trata de un material bastante transparente, es decir, poco difusor. Para este caso podemos comparar el índice de refracción del $I K B(1,55)$ con el del cinabrio $(2,81)$ y el del acetato de polivinilo $(1,46)$, pues si los pigmentos deben tener índices de refracción mucho más altos que el del aglutinante para cubrir por 
refracción y reflexión, el $I K B$ es mucho más transparente que el cinabrio. El caso del brillo rasante (sheen) es importante, porque los materiales poco brillantes tienen un componente especular muy notable cuando se observan en ángulos rasantes, hecho que se debe al fenómeno físico del índice de refracción del aglutinante en consideración al índice de refracción del aire (n =1). Para determinar este tipo de brillo observamos la superficie de manera rasante bajo la incidencia de un haz de luz perpendicular a ella. Podemos establecer la reflectancia $(\rho)$ de la superficie para un ángulo de incidencia nulo $(i=0)$ del modo siguiente:

$$
\rho(0)=[(\mathrm{n}-1) /(\mathrm{n}+1)]^{2}
$$

Por tanto, si para el acetato de polivinilo utilizado el índice es $n=1,46$, entonces la reflectancia es $\rho(0)=0,03$ y este valor es relativamente pequeño si tenemos en cuenta que el mismo tipo de reflectancia es de 0,04 en el vidrio que aceptamos para proteger trabajos sobre papel. Así pues, Klein conseg(uiría) una superficie considerablemente mate. El lustre (luster) es otro tipo de brillo caracterizado por el contraste entre las áreas que reflejan especularmente y las otras, de manera que puede realzar la textura. No obstante, la textura aterciopelada que provocaba en John Gage (1993, p. 267) una sensación de ABSOLUTA ESPIRITUALIDAD no es "resultado de", pero aparece "gracias a" que la superficie pose(ería) precisamente una textura a causa de la poca cantidad de polivinilo que aglutin(aría) las partículas de pigmento; es decir, en la parte superior de la capa pictórica no se form(aría) una película sólo de aglutinante, o incluso pod(rían) haber partículas mal humectadas que tienden a flotar sobre la superficie formando una neblina de partículas imperceptibles que impiden el reflejo (véase Figura 10).

Así evit(aría) cualquier leve lustre y su textura no aparec(ería) realzada sino como la del terciopelo, que sólo brilla cuando sus fibras están perfectamente orientadas provocando una dirección dominante de difusión - o lo que es lo mismo, la reflexión especular. Empero, no existen pigmentos naturales de grano perfectamente esférico y los artificiales son redondos de una manera tosca, por lo que la superficie del $I K B$ no puede ofrecer una difusión uniforme y no será jamás perfectamente mate (véase Figura 11). 

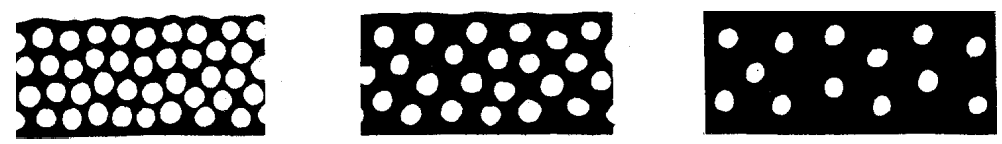

Figura 10. A la derecha, una capa de pintura seca con más aglutinante que pigmento y tal exceso ha nivelado la superficie por encima de las partículas, lo que provoca una superficie brillante por favorecer la reflexión especular. En el esquema siguiente, la proporción de aglutinante es intermedia y, así, el efecto del acabado será semimate como el de una cáscara de huevo. A la izquierda vemos cómo una cantidad de aglutinante suficiente para rodear las partículas y aglutinarlas pero que no rebosa, produce una superficie más áspera que reflejará la luz en todas direcciones produciendo un efecto mate. Dibujo del autor.

Con todo, sí que conseg(uiría) un azul particularmente azul en sus esponjas, pues la luz penetra en sus alvéolos donde las reflexiones múltiples sobre las paredes internas permiten que éstas absorban la luz, que así aparece filtrada — más pura. De este modo, Klein vuelve a mostrarse como homme averti porque incluso aprovecha el fenómeno físico que conocemos como ley de Lambert

Cuando un material difunde la radiación que incide sobre él, se le denomina difusor; si parte del flujo incidente lo atraviesa y es transmitido, se dice que el material es translúcido. Si en cambio el material es opaco y sólo hay flujo reflejado o absorbido, se dice que éste es mate o semimate, según sea importante o no, la fricción reflejada difusamente. Un difusor perfecto o ideal [mate ideal] es aquel en el cual para cualquier ángulo de incidencia del haz, el flujo reflejado posee una intensidad igual a la prevista por la ley de Lambert." (...) "Esta ley, también conocida como ley del coseno, se enuncia diciendo que una fuente plana de dimensiones finitas tiene en una dirección dada, una intensidad energética proporcional al coseno del ángulo que forma esa dirección con la normal a la superficie. (Lozano, 1978, p. 147, p. 86). 

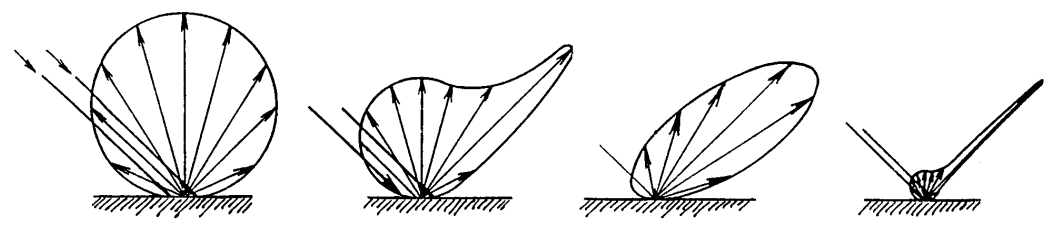

Figura 11. De izquierda a derecha: la reflexión teórica producida por un difusor perfecto, la típica de una superficie altamente difusora o mate, la de una medianamente difusora o semimate, y la producida por una poco difusora o brillante.

Por tanto, si el color $I K B$ puede ganar o perder intensidad a causa de la variación del flujo luminoso según su aplicación en distintos objetos, no podemos sostener que sea el mismo para cualquier superficie gracias a la maleabilidad que permite el acetato de polivinilo. Entonces, MancusiUngaro debería establecer cuál de los IKB es NUEVO; así como Alison Cole tendría que determinar cuál es el más BRILLANTE y cual es en realidad el excepcionalmente INTENSO. Después de haber comprendido cómo aparece la diferencia de color y sus causas, incluso podemos afirmar que no se(ría) el mismo en cada cuadro. Esto es importante porque para ofrecer idénticos $I K B$ debe mantener la misma composición química y tamaño de partícula de un pigmento utilizado desde 1954 para sostener su intensidad, tono y subtono durante la década de los sesenta. Esto es difícil aunque posible, pero lo que podemos dudar es que logre mantener la misma disposición de las partículas en los diversos objetos de la serie $I K B$, en varios lienzos, o incluso en la tonalidad de la superficie pintada en uno sólo de ellos.

Este aspecto es el más problemático porque atañe a la pintura líquida, que condiciona la aplicación y, así, sus características iniciales cuando la capa finalmente seca. Si Klein conseg(uía) una capa uniforme gracias a su aplicación con rodillo, este útil le obliga a trabajar con la viscosidad próxima a una pasta $y$, en tal caso, una fluidez insuficiente produc(iría) marcas diagonales en el recubrimiento. La bibliografía sobre sus lienzos no referencia estas marcas, lo que evidenci(aría) que trabaja con la fluidez 
correcta. Algo que consigue mediante una buena mojabilidad del pigmento gracias a que emplea disolventes lentos: alcohol etílico al 95 por ciento y acetato de etilo para disolver las bolitas de acetato de polivinilo que aglutinarán las partículas de azul ultramar (Mancusi-Ungaro, 1983).

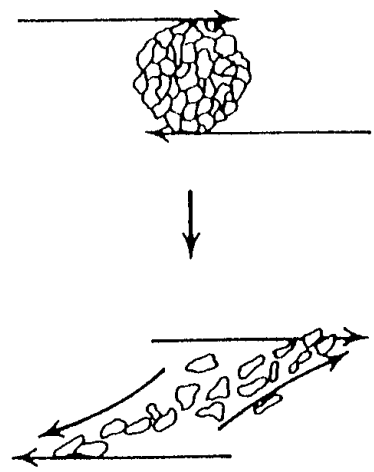

Figura 12. Aglomerado de partículas de pigmento que podemos deshacer simplemente girándolo como una bola bajo dos fuerzas coordinadas. Sin embargo, es imposible lograr una distribución uniforme sólo por deshacer el aglomerado. Dibujo del autor adaptado de Patton (1979).

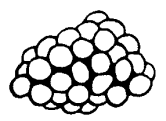

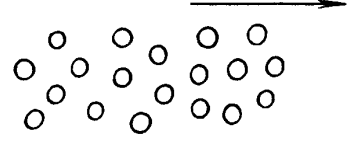

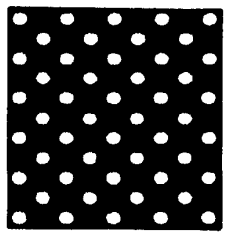


Ambos son disolventes volátiles oxigenados, cuya velocidad de cambio de estado líquido a vapor es intermedia o bastante lenta en comparación con otros. La función del disolvente durante la evaporación es controlar las características del flujo de la película que se está formando. Por tanto, si se evapora demasiado deprisa, la capa de pintura no mojará suficientemente bien el pigmento ni el sustrato y, así, no tendrá una buena adherencia. En este caso, la lentitud del disolvente favorece que la pintura elaborada por Klein pueda aplicarse a cualquier objeto.

El pigmento siempre suele manipularse en su estado aglomerado; es decir, se encuentra formando un grupo de partículas secas que se mantienen unidas por las fuerzas superficiales de sus caras. Podemos eliminarlo con una molturación antes de su mezcla con el aglutinante. Sin embargo, después de mezclado puede producirse un empaquetado de partículas debido a la floculación, pues sus fuerzas electromagnéticas las atraen reaglomerando el pigmento una vez dispersado en el líquido.

Probablemente, la fuerza mecánica de la aplicación a rodillo (igual que a brocha o pistola) elimina el flóculo del modo que indicamos en la figura 13. No obstante, aquella lentitud de la evaporación del disolvente puede permitir la formación de nuevos flóculos durante el secado de la pintura. Algo que no permit(iría) la sensación monocroma afirmada por Klein, puesto que la variación de la intensidad de su azul se(ría) evidente a causa de la diferencia de tamaño entre las partículas y los empaquetados de diferente envergadura.

Además, la floculación provocará diferente opacidad de la pintura, hecho importante porque el pigmento para la preparación del soporte vimos que no es el mismo y esto no sólo aumenta la luminosidad por la reflexión del sustrato blanco de manera desigual en cada $I K B$ debido al diferente índice de refracción del pigmento utilizado, sino que logrará variar el tono porque tampoco amarillean igual (véase Figura 8). Todo acrecentado porque el poder cubriente y colorante de este tipo de azul son escasos.

Los pigmentos son mayoritariamente hidrofílicos y, por tanto, se mojan mal con recubrimientos orgánicos que son hidrófobos. Así que Klein elige bien su aglutinante, pues la resistencia a los álcalis y la naturaleza hidrofílica del azul ultramar le hace útil en las pinturas de acetato de polivinilo porque es un medio hidrófilo y con un $\mathrm{pH}$ bastante alto. Entonces, tal afinidad pod(ría) garantizar un recubrimiento uniforme. 
No obstante, el problema de la uniformidad de color sigue latente en lo referente a la viscosidad. Los pigmentos negros cubren principalmente por absorción de todas las longitudes de onda y los pigmentos blancos cubren por reflexión, refracción y poca absorción; pero los pigmentos coloreados más o menos transparentes cubren mediante los tres procesos: reflejan, refractan, y absorben los rayos de luz en una proporción que depende de la particularidad del pigmento - vimos la importancia de su naturaleza química y del tamaño y forma de su partícula. Klein solicita una patente oficial para sus diferentes proporciones de ultramarino, acetato de polivinilo, alcohol etílico y acetato de etilo según el útil a emplear y el objeto a recubrir (Mancusi-Ungaro, 1983), por lo que trabaja con diferentes viscosidades. La viscosidad es debida a la diferente concentración de pigmento. Así que con diferentes viscosidades según el objeto, provocará diferentes difusiones. Por tanto, para mantener la uniformidad de color en cada objeto -0 en todos sus lienzos - debe lograr que las partículas guarden la misma separación para mantener una idéntica distribución de centros difusores, con lo que logr(aría) re-emitir las mismas ondas electromagnéticas en toda la superficie (véase Figura 8).

Para ello, necesita de espaciadores, así que entre las partículas de azul ultramar deb(eríamos) encontrar partículas de un pigmento cuya refractancia no interfiera con la transmisión lineal de la luz, para lo que el límite de su tamaño debe ser $0.4 \mu$ porque corresponde a la mitad de la longitud de onda de la luz, magnitud por debajo de la cual el pigmento empieza a desaparecer ópticamente. Sin embargo, el análisis químico de Sonoda, Rioux y Duval (1993, p. 116) sólo detecta azul ultramar puro sin espaciadores, sin aditivos dispersantes que impidan la floculación gracias a influir sobre la carga electromagnética, y sin cargas que ayuden a que la pintura sea mate.

Ante tal carencia, sus características ópticas pueden verse alteradas por la distancia entre partículas. Sabemos que en una capa de pintura los rayos de luz chocan con los millones de partículas en todos los ángulos de incidencia refractándose y reflejándose en todas direcciones mientras penetran o abandonan estas partículas de pigmento, por lo que si esta difusión debe ser uniforme, la inferencia de los rayos de luz incidentes (véase Figura 8 y Figura 2) tiene que disponer no sólo de igual magnitud de partículas transparentes sino del mismo espacio de aglutinante entre ellas. Este espacio 
debe ser cercano a la longitud de onda de la luz, pues así obtiene la máxima probabilidad de que la red de partículas de pigmento infiera la transmisión de rayos de luz. De modo que Klein debe lograr su separación óptima para mantener el mismo rendimiento al IKB durante toda la superficie, si quiere sostener la sensación monocroma de su argumentación. Tras discernir mediante el auxilio de la metodología de la ciencia del color, podemos entender la afirmación con la que Molnar (1992, p. 80) cierra su escritura sobre un Yves Klein policromático: el $I K B$ no es monocromo, pero esta presentación del estímulo verbal y visual parece ser un problema de las artes plásticas -aquí lo hemos intentado demostrar.

Recapitulando. La curva de reflectancia espectral del IKB evidencia que contiene casi lo mismo de rojo que de azul (véase Figura 6). Un pigmento artificial sólo es esférico de una manera tosca, por lo que la superficie no podrá ofrecer una difusión uniforme y no será jamás perfectamente mate, pero Klein la consigue bastante mate y el brillo no modificará el color según nuestro ángulo de visión. El disolvente utilizado permite un control perfecto de la viscosidad de la pintura y, así, puede aplicarse casi sobre cualquier cosa. No obstante, si varía la viscosidad para poder aplicar la pintura sobre cualquier objeto, varía el flujo luminoso que puede alterar su curva de reflectancia espectral. Además, debe mantener las características de las partículas de pigmento y su distribución para ofrecer la misma característica óptica en cada objeto o incluso en un mismo lienzo, donde la preparación al óleo y el acetato de polivinilo como aglutinante de la capa pictórica no consiguen ofrecer la PUREZA del azul ultramar ni la estabilidad con la que Klein pretende lograr IKB-s idénticos. Tampoco logra la excepcional INTENSIDAD pues su vibración visual es debida a su re-emisión de energía en el área espectral del rojo, que es el subtono del azul caracterizado por la longitud de onda dominante.

Todo esto puede parecernos exagerado pero, probablemente sea debido a una larga formación que desatendió el cuerpo que la conformó (Fortuny, 1996). Por ejemplo, el ojo humano puede distinguir una señal luminosa de 1/1000 de bujía a la distancia de un kilómetro. La energía de dicha excitación es tan ínfima que para calentar $1 \mathrm{~cm}^{3}$ de agua a $1^{\circ}$ de temperatura con la ayuda de la misma se requerirían sesenta mil años (Luria 1984, p. 33). El problema radica, pues, en la capacidad de discernir 
"Es bien notorio que la diferenciación de los matices de colorido, de alteraciones insignificantes del tono o de cambios gustativos mínimos, puede agudizarse verticalmente como resultado de la actividad profesional. Se ha establecido que los tintoreros logran distinguir entre cincuenta y sesenta matices del color negro" (Luria 1984, p. 52)

Klein hubiera tenido una oportunidad si el vehículo de su valor expresivo fuera semejante a la complejidad química del azul Maya, o la pretendida excepcionalidad hubiera sido la de un azul como el de las pinturas murales de Vall de Boí, pues el análisis fisicoquímico establece que no corresponde exactamente a ningún pigmento citado en la bibliografía, sino a un indefinido mineral aerinita (Tura, 1988; Pedrola, 1988). Quizás si hubiera sido capaz de crear su propio estímulo intelectual como lo hicieran con el azul egipcio que, aun siendo similar al utilizado durante toda la antigüedad, fue el primer pigmento obtenido artificialmente del que tenemos noticia (Le Fur, 1990; Guichard \& Guineau, 1990; Angelini, 1990). Pero Klein quizás no supo elegir el azul idóneo, pues toma el Pigment Blue 29, que es el producto fabricado con menos diversidad.

Podemos mostrarnos escépticos pensando que hace demasiado tiempo que juzgamos la obra de arte como para que ahora resulte que lo hacemos mal. Pues bien, basta citar los dos ejemplos más conocidos para temerlo: la limpieza de Las Meninas de Velázquez descubrió que su color sólo era un espejismo y desmitificó las erróneas interpretaciones que conspicuos críticos venían reiterando en cada juicio de valor (Campo, 1989), y lo mismo ocurrió en la Capilla Sixtina (Vecchi, 1995). La luz altera los electrones, que rompen las cadenas moleculares de carbono, hidrógeno y oxígeno que las componen para que lo primero que pierda el arte sea su color (Bruhms, 1996, p. 198). Si del mismo modo que Arnheim (1986, p. 378), pretendemos quitarle importancia a este hecho y conformarnos con la vaguedad de las formas de una diapositiva en blanco y negro, podemos intentar juzgar una obra de Rothko, cuyas manchas de color nada tienen que ver hoy con las de ayer, porque sus colores orgánicos son fácilmente alterables (Cole, 1994, p. 59).

Incluso Barthes, para quien la materia no es materialista en sí sino infinitamente simbólica, reconoce lo obvio (1986, p. 218) de la materia ante lo obtuso de una representación inevitablemente simbólica cuando sostiene 
el doble origen de la verdad de la pintura: la materia como proyección del cuerpo y la maestría del ojo para arrebatar su acepción de símbolo. Ambos orígenes conformarían la especificidad estética del arte que Barthes cree perdida a causa de la crisis histórica de la reproducibilidad técnica de los materiales. Por tanto, no deberíamos oponernos a recuperar lo propiamente estético bajo la perspectiva de juicio de la eficacia de una propuesta a través de la confirmación de la experiencia.

La sospecha que inició nuestra investigación pasó a una hipótesis firme cuando atendimos a que cualquier pigmento es impuro y de luz débil si lo comparamos con los colores del espectro, pues la suma de todos los colores pigmento no da el blanco sino un gris sucio. Entonces, un pigmento nunca será monocromático, de lo contrario no ocurrirían la mayoría de los efectos que consiguen los artistas al mezclar colores. Por tanto, Klein nunca hubiera conseguido una sensación monocroma con ellos. Para conseguir así el auténtico concepto monochromos, es decir, una distribución espectral que ya no es determinada por una curva sino por una perpendicular al nanómetro correspondiente a su intensidad como muestra la Figura 14, más bien debería de haber utilizado una red de difracción de la luz mediante partículas opacas -algo bastante complicado (Nassau, 1983, p. 274). También lo hubiera logrado al tallar cincuenta mil trazos paralelos por centímetro cuadrado en una pieza óptica (Lozano, 1978, p. 118). Un láser (Mauldin, 1992, p. 243) hubiera sido el modo más sencillo, pero queda fuera de nuestra cuestión.
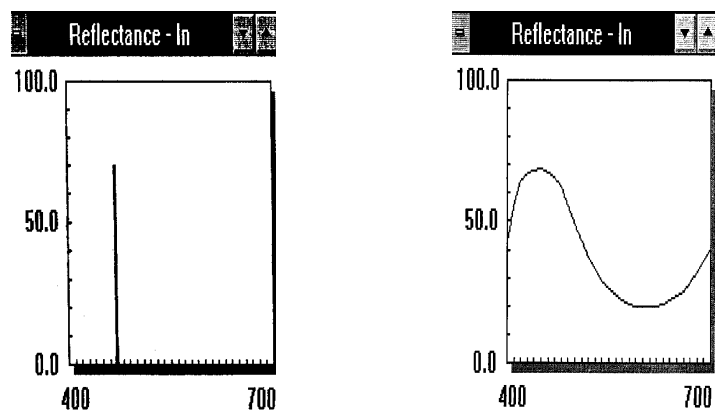

Figura 14. A la izquierda: distribución espectral de la reflectancia de un azul monocromático, y a la derecha la distribución del azul ultramar IKB. Representación del autor adaptada de Molnar (1992). 
Por lo común, los críticos de arte suelen pensar que esto no tiene importancia, porque la intención del artista es lo que cuenta, y ésta es relatada con palabras, que son las que fluyen por su mente teórica para recrear su argumentación. Esta viene siendo la tarea del crítico y, así, la actividad artística dejó de consistir en una práctica iniciando una metamorfosis hacia la retórica, donde todos idean sobre la idea gracias a una visión sin mirada. Por supuesto, como puede ser la nuestra, porque todo nuestro análisis se basa en un incierto confero bibliográfico. Así, nuestra crítica a la visión sin mirada de la críticos queda como ejemplo metacrítico, pues no hay mejor manera de evidenciar la condición de un lenguaje que por no atender al artefacto deb(ería) verbalizar en condicional. El crítico quizá insista en sostener que la adjetivación monochrome del color no es un problema de importancia capital, sino una simple cuestión de vocabulario. Sin embargo, el artista no puede dejar de sentir y pensar al mismo tiempo en interacción con la materia, porque la teoría la hace durante el propio hacer del proceso creativo, y de ahí la sospecha -mirar sin sentir es un contrasentido.

\section{Referencias}

Allen, R. L. M. (1970). Color chemistry. London: Nelson.

Angelini, Emma et al. (1990). Plasma source mass spectrometric analysis of ancient egyptian pigments. En GUINEAU, Bernard (ed.). Pigments et colorants de l'antiguité et du moyen âge: teinture, peinture, enluminure. Etudes historique et physico-chimiques (p. 117). París:

Centre National de la Recherche Scientifique. (Colloque International du CNRS).

Aracil, Alberto, \& Rodriguez, Delfín (1982). El siglo XX. Entre la muerte del arte y el arte moderno. Madrid: Istmo.

Argan, Giulio Carlo (1984). El arte moderno 1770-1970. (6 ed.). Valencia: Fernando Torres.

Arnheim, Rudolf (1980). Hacia una psicología del arte. Arte y Entropía.

Madrid: Alianza Editorial. (Alianza Forma, 13).

Arnheim, Rudolf (1986). Psicología del ojo creador. (Nueva versión, $7^{\mathrm{a}}$ ed.). Madrid: Alianza Editorial. (Alianza Forma, 3). 
Barthes, Roland (1986). Lo obvio y lo obtuso. Imágenes, gestos, voces.

Barcelona: Paidós. (Paidós Comunicación, 21).

Beardsley, C. Monroe, \& Hospers, John (1982). Estética. Historia y

fundamentos. (5a ed.). Madrid: Cátedra. (Teorema).

Bruhms, Johanna María Theile. (1996). El libro de la restauración. Madrid:

Alianza, (El Libro de Bolsillo-Libros Útiles, 1799).

Buxbaum, Gunter (ed.). (1993). Industrial inorganic pigments. Weinheim: $\mathrm{VCH}$.

Campo, Angel del (1989). La magia de Las Meninas: una iconologia velazqueña. ( $4^{\mathrm{a}}$ ed. aum.). Madrid: Colegio de Ingenieros de Caminos, Canales y Puertos. (Colección de Ciencias, Humanidades e Ingeniería, 7).

Cole, Alison (1994). Color. Barcelona: Blume Libros. (Testimonio Visual del Arte).

Crighton, J. S. Degradation of polymeric materials. En Eaton, Linda, \& Meredith, Clare (ed.). Modern organic materials (p. 11). Edinburg: The Scottish Society for Conservation \& Restoration, 1988. (Preprints of the Meeting SSCR).

Chauvel, Annik, \& Roire, Jacques (1985). Peindre pourquoi, sur quoi, avec quoi, comment. Puteaux: Erec Éditeur. (Livres de Technologie de 1'AFTPV).

Doerner, Max. (1991). Los materiales de pintura y su empleo en el arte. (5 reimpr.). Barcelona: Reverté.

El Telar. (1951). La alteración de cuadros al óleo. Ibérica, 14 (223), p. 453.

Fortuny, Jaume (1996, octubre). El tractament de l'espai i el volum al currículum de l'Àrea Visual i Plàstica de l'ensenyament primari i secundari obligatori. Una proposta crítica. En IX Trobada de Plástica. Barcelona: Institut de Ciències de 1'Educació de la Universitat Barcelona, p. 11.

Gage, John (1993). Color y cultura. La práctica y el significado del color de la Antigüedad a la abstracción. Madrid: Siruela. (La Biblioteca Azul, Serie Mayor, 1).

Gall, L. (1971). The colour science of pigments. Ludwigshafen-am-Rhein, B.A.S.F. 
Goldstein, E. Bruce (1993). Sensación y percepción. (3a reimpr.). Madrid: Debate.

González Martin, Jesús (1994). La pintura como recubrimiento protector. Madrid: A. Madrid Vicente.

Guichard, Vincent, \& Guineau, Bernard (1990). Identification de colorants organiques naturels dans des fragments de peintures murales de l'Antiguité. En Guineau, Bernard (ed.). Pigments et colorants de l'antiguité et du moyen âge: teinture, peinture, enluminure. Etudes historique et physico-chimiques (p. 245). París: Centre National de la Recherche Scientifique. (Colloque International du CNRS). Hurvich, Leo (1981). Color vision. Sunderland, Mass: Sinauer Associates. Judd, Deane B., \& Kelly, Kenneth L. (1955). The ISCC-NBS method of designating colors and a dictionary of color names. Washington: United States Departament of Commerce. (National Bureau of Standards Circular, 553).

Kamber, Richard (1993). A modest proposal for definding a work of art. The British Journal of Aesthetics, 33 (4), p. 313.

Le Fur, Daniel. (1990). Le pigments dans la peinture égyptienne. En Guineau, Bernard (ed.). Pigments et colorants de l'antiguité et du moyen âge: teinture, peinture, enluminure. Etudes historique et physico-chimiques (p. 181). París: Centre National de la Recherche Scientifique. (Colloque International du CNRS),

Lozano, Roberto Daniel (1978). El color y su medición. Buenos Aires: Américalee.

Luria, Alexander Romanovich (1984). Sensación y percepción. Barcelona:

Martínez Roca. (Libros Universitarios y Profesionales, Breviarios de Conducta Humana).

Mauldin, John H. (1992). Luz, laser y óptica. Madrid: McGraw-Hill. McAdam, David L. (1985). Color measurement. Theme and variations. ( $2^{\mathrm{a}}$ ed. rev.). Berlin: Springer-Verlag. (Springer Series in Optical Sciences, 27).

McLaren, K. (1986). The colour science of dyes and pigments. ( $\left.2^{\mathrm{a}} \mathrm{ed}.\right)$. Bristol: Adam Hilger Ltd.

Mancusi-Ungaro, Carol (1983). Fiche technique sur IKB. En Mock, JeanYves (ed.). Yves Klein (p. 247). París: Centro Georges Pompidou. 
Mayer, Ralph (1993). Materiales y técnicas del arte. ( $2^{\mathrm{a}}$ ed. revisada y ampliada). Madrid: Tursen-Hermann Blume.

Molnar, François (1992). Yves Klein le polychrome. Revue d'Esthétique, 21, p. 71.

Nassau, Kurt. (1980, diciembre). Las causas del color. Investigación y Ciencia, 51, p. 56.

Nassau, Kurt. (1983). The physics and chemistry of color. The fifteen causes of color. New York: Wiley Interscience.

Osborne, Roy (1980). Ligths and Pigments: Color principles for artists. New York: Harper \& Row.

Osborne, Roy (1990). Teaching colour: a personal view. The Artist, 4, p.14.

Parker, Dean. (1970). Tecnología de los recubrimientos de superficies. Bilbao: Urmo. (Enciclopedia de la Química Industrial, 7).

Patton, Temple C. (1979). Paint, flow and pigment dispersion. A rheological approach to coating and ink technology. ( $2^{\mathrm{a}} \mathrm{ed}$.). New York: Wiley $\&$ Sons.

Pedrola, Antoni (1988). Materials, procediments y técniques pictóriques. $\left(2^{\mathrm{a}}\right.$ ed.). Barcelona: Publicacions de la Universitat de Barcelona. (Materials Docents, 3).

Ramos, M.A., \& De Maria, M.R. (1988). Ingeniería de los materiales plásticos. Madrid: Díaz de Santos.

Roy, Ashok (ed.) (1993). Artists' Pigments. A handbock of their history and characteristics. (Vol. II). Washington-New York: National Gallery of Art-Oxford University Press.

Society of Dyers and Colourist (1975). Colour Index. ( $3^{\mathrm{a}}$ ed. rev.). Bradford: The Society of Dyers and Clourist.

Sonoda, Naoko; Rioux, Jean-Paul; \& Duval, Alain Rene (1993).

Identification des materiaux synthetiques dans les peintures modernes. Pigments organiques et materie picturale. Studies in Conservation, 2, p. 99.

Tura, J. M. (1988). Study of the blue pigments of the mural paintings of the Vall de Boí by means of SEM / EDXA. Beiträge zur Elecktronenmikroskopischen Direktabbildung von Oberflächen, 21, p. 293. 
Van Lier, Henri (1971). Objeto y estética. Moles, Abraham et al. (1969). Los objetos (p. 129). Buenos Aires: Tiempo Contemporáneo. (Biblioteca de Ciencias Sociales, Comunicaciones, 13).

Vecchi, Oier Luigi de (ed.). (1995). La Capilla Sixtina. Una restauración histórica. Madrid: Nerea.

Westphal, Joathan (1989). Black. Mind, 10, p. 585.

Zollinger, Heinrich. (1991). Color Chemistry. (2a. ed. rev.). Weinheim: $\mathrm{VCH}$.

Jaume Fortuny Agramunt: Artista plástico. Profesor de Dibujo en la Facultad de Bellas Artes de la Universidad de Barcelona. Profesor de Representación en el Grado Universitario en Artes y Diseño de la Escuela Massana, centro adscrito a la Universidad Autónoma de Barcelona. Crítico de arte miembro de la Asociación Catalana de Críticos de Arte (ACCA, Barcelona) y de la Association Internationale des Critiques d'Art (AICA, París).

Contact Address: Facultat de Belles Arts. Departament d'Arts i Conservació-Restauració. Secció de Dibuix. Pau Gargallo, 4. 08028 Barcelona. España.

Escola Massana. Universitat Autònoma de Barcelona. Grau en Arts i Disseny. Departament de Representació. Hospital, 56. 08001 Barcelona. España.

E-mail address: jaume.fortuny@ub.edu jaume.fortuny.agramunt@gmail.com 